\title{
Article \\ Effects of Synthesis Parameters on the Crystallization Profile and Morphological Properties of SAPO-5 Templated by 1-Benzyl-2,3-Dimethylimidazolium Hydroxide
}

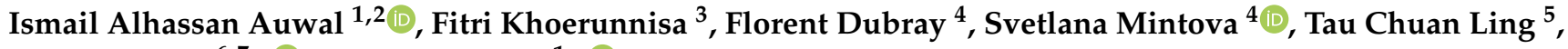 \\ Ka-Lun Wong ${ }^{6,7, *(\mathbb{D})}$ and Eng-Poh $\mathrm{Ng}^{1, * \mathbb{D}}$ \\ 1 School of Chemical Sciences, Universiti Sains Malaysia, Pulau Pinang 11800, Malaysia; \\ sahiburrahmah@gmail.com \\ 2 Chemistry Department, Faculty of Natural and Applied Sciences, Sule Lamido University, \\ PMB 048 Kafin Hausa, Jigawa State, Nigeria \\ 3 Department of Chemistry, Universitas Pendidikan Indonesia, Setiabudi 229, Bandung-40154, West Java, \\ Indonesia; fitri@upi.edu \\ 4 ENSICAEN, UNICAEN, CNRS, Laboratoire Catalyse et Spectrochimie, Normandie Université, \\ 14000 Caen, France; florent.dubray@ensicaen.fr (F.D.); mintova@ensicaen.fr (S.M.) \\ 5 Institute of Biological Sciences, Faculty of Science, University of Malaya, Kuala Lumpur 50603, Malaysia; \\ tcling@um.edu.my \\ 6 School of Energy and Chemical Engineering, Xiamen University Malaysia, Sepang 43900, Malaysia \\ 7 College of Chemistry and Chemical Engineering, Xiamen University, Xiamen 361005, China

Citation: Auwal, I.A.; Khoerunnisa, F.; Dubray, F.; Mintova, S.; Ling, T.C.; Wong, K.-L.; Ng, E.-P. Effects of Synthesis Parameters on the Crystallization Profile and

Morphological Properties of SAPO-5 Templated by 1-Benzyl-2,3Dimethylimidazolium Hydroxide. Crystals 2021, 11, 279. https:// doi.org/10.3390/cryst11030279

Academic Editor:

Sendhil Poornachary

Received: 22 February 2021

Accepted: 8 March 2021

Published: 12 March 2021

Publisher's Note: MDPI stays neutral with regard to jurisdictional claims in published maps and institutional affiliations.

Copyright: () 2021 by the authors. Licensee MDPI, Basel, Switzerland. This article is an open access article distributed under the terms and conditions of the Creative Commons Attribution (CC BY) license (https:// creativecommons.org/licenses/by/ $4.0 /)$.

\begin{abstract}
The formation of SAPO-5 molecular sieves is studied under hydrothermal conditions in the presence of a new templating agent, 1-benzyl-2,3-dimethylimidazolium hydroxide ([bzmIm]OH). The syntheses were carried out by varying the synthesis parameters, viz. crystallization temperature, heating time and reactants molar composition $\left(\mathrm{SiO}_{2}, \mathrm{Al}_{2} \mathrm{O}_{3}, \mathrm{P}_{2} \mathrm{O}_{5},[\mathrm{bzmIm}]^{+}, \mathrm{H}_{2} \mathrm{O}\right)$ in order to investigate the role of each synthesis parameter on the formation of SAPO-5. The results showed that these synthesis parameters had significant influences on the entire crystallization process (induction, nucleation, crystal growth, and Ostwald ripening) and physicochemical properties of SAPO-5 (morphology and crystal size). Moreover, this study also demonstrated a fast hydrothermal synthesis approach where a SAPO-5 molecular sieve with hexagonal prism morphology could be crystallized within $10 \mathrm{~h}$ instead of days using a novel [bzmIm] OH heterocyclic template, thus offering an alternative route for synthesizing zeolite-like materials for advanced applications.
\end{abstract}

Keywords: SAPO-5; microporous material; hydrothermal synthesis; imidazolium template; crystallization process

\section{Introduction}

Aluminophosphate (AlPO- $n$ ) and silicoaluminophosphate (SAPO- $n$ ) microporous solids are zeolite-like materials that are widely used in catalysis, adsorption, and separation processes [1,2]. Typically, SAPO-5 is among the most important zeotype materials due to its mild acid strength, unidimensional pore channel system, and large pore mouth opening $\left(0.73 \times 0.73 \mathrm{~nm}^{2}\right)[3]$.

SAPO- 5 can be readily crystallized under hydrothermal conditions at $180-200{ }^{\circ} \mathrm{C}$ for 1-3 days in the presence of alkylamine organic templates, such as triethylamine, tripropylamine, tetraethylammonium hydroxide, tetrabutylammonium hydroxide, and $\mathrm{N}$-methyldicyclohexylamine [4-8]. The use of so-called structure-directing agents (SDAs) with different molecular shapes, sizes, and polarities have been found to form SAPO-5 crystals with different morphological and physicochemical properties $[9,10]$. Isomorphous Si substitution, surface area, particle size and surface acidity of the SAPO-5 samples are affected when different SDAs are used in the crystallization process. 
Recently, imidazolium compounds have been explored as novel SDAs in the synthesis of AlPO-5 and SAPO-5 materials [11,12]. Unlike aliphatic amines, the delocalized $\pi$ electrons in their cyclic ring together with their bulkier molecules create a versatile platform for adding functional properties and chemical modifications, thus altering the overall crystallization process of SAPO-5 materials $[13,14]$. The crystallization rate, crystallinity and solid yield can be tuned by using imidazolium templates with different substituted groups [10]. Besides SDAs, the crystallization process of SAPO-5 might also be affected by the synthesis parameters such as heating time, crystallization temperature, synthesis technique, amount and source of reactants, solvent, and aging [15]. Nevertheless, the knowledge about the impacts of those synthesis parameters on the crystallization and morphology of SAPO-5 templated by imidazolium SDA are still not well understood and hence are worth further investigation.

In this work, the crystallization and morphological profiles of SAPO-5 templated by 1-benzyl-2,3-dimethylimidazolium hydroxide as a novel SDA is studied by carefully controlling the synthesis parameters. The formation mechanism of SAPO-5 is then proposed based on the X-ray diffraction and microscopy data obtained.

\section{Experimental}

\subsection{Synthesis of 1-Benzyl-2,3-Dimethylimidazolium Chloride, $[\mathrm{bzmIm}] \mathrm{Cl}$}

Typically, 1,2-dimethylimidazole (30.00 g, 98\%, Merck, Darmstadt, Germany) was first dissolved in ethanol (40 mL, 99.7\%, QRëc, New Zealand) in a 250-mL round-bottom flask before benzyl chloride (66.00 g, 99\%, Merck, Darmstadt, Germany) was added. The resulting mixture was refluxed for $7 \mathrm{~h}$ at $100{ }^{\circ} \mathrm{C}$ under stirring. The shiny white crystalline solid formed was then purified with acetone several times before it was dried at $100{ }^{\circ} \mathrm{C}$. The resulting product was [bzmIm] Cl with a solid yield of $87.09 \%$ (Scheme 1$).{ }^{1} \mathrm{H} \mathrm{NMR}$ $\left(400 \mathrm{MHz}, \mathrm{ppm}, \mathrm{D}_{2} \mathrm{O}\right): \delta=2.48\left(3 \mathrm{H}, \mathrm{s}\right.$, imidazole $\left.\mathrm{N}-\mathrm{C}\left(\mathrm{CH}_{3}\right)-\mathrm{N}\right), 3.70(3 \mathrm{H}, \mathrm{s}$, imidazole N$\left.\mathrm{CH}_{3}\right), 5.28\left(2 \mathrm{H}, \mathrm{s}\right.$, imidazole $\left.\mathrm{N}-\mathrm{CH}_{2}-\mathrm{C}_{6} \mathrm{H}_{5}\right), 7.22(1 \mathrm{H}, \mathrm{d}, \mathrm{J}=3 \mathrm{~Hz}$, imidazole N-CH=CH-N), $7.24(1 \mathrm{H}, \mathrm{d}, \mathrm{J}=3 \mathrm{~Hz}$, imidazole $\mathrm{N}-\mathrm{CH}=\mathrm{CH}-\mathrm{N})$ and $7.28-7.41\left(5 \mathrm{H}\right.$, phenyl). FT-IR $\left(\mathrm{cm}^{-1}, \mathrm{KBr}\right.$ disk): 3074 (=C-H stretching), 2948 (C-H stretching), 1598 and 1452 (aromatic $\mathrm{C}=\mathrm{C}$ ), 1020 (imidazolium, $\mathrm{C}-\mathrm{N}$ ), 1536 (imidazolium, $\mathrm{C}=\mathrm{N}$ ). Anal. cacld for $\mathrm{C}_{12} \mathrm{H}_{15} \mathrm{~N}_{2} \mathrm{Cl}$ : $\mathrm{C}, 64.72 \%$; $6.79 \%$; N , 12.58\%; Cl, 15.92\%; found: C, 65.03\%; H, 6.66\%; N, $11.55 \% ; \mathrm{Cl}, 16.77 \%$.

\subsection{Preparation of 1-Benzyl-2,3-Dimethylimidazolium Hydroxide ([bzmIm]OH) Solution}

The $[\mathrm{bzmIm}] \mathrm{OH}$ template solution was prepared by ion exchanging the $[\mathrm{bzmIm}] \mathrm{Cl}$ ionic salt with Amberlite ${ }^{\circledR}$ IRN-78 hydroxide ion-exchange resin (Sigma-Aldrich, St. Louis, MO, USA). The resulting solution was separated from the resins by filtration and titrated with $0.1 \mathrm{M} \mathrm{HCl}$ solution where $90 \% \mathrm{OH}^{-}$ion exchange was achieved. The hydroxide solution was then concentrated to $33.0 \mathrm{wt} \%$ at $50{ }^{\circ} \mathrm{C}$ before it was further used for SAPO-5 synthesis.

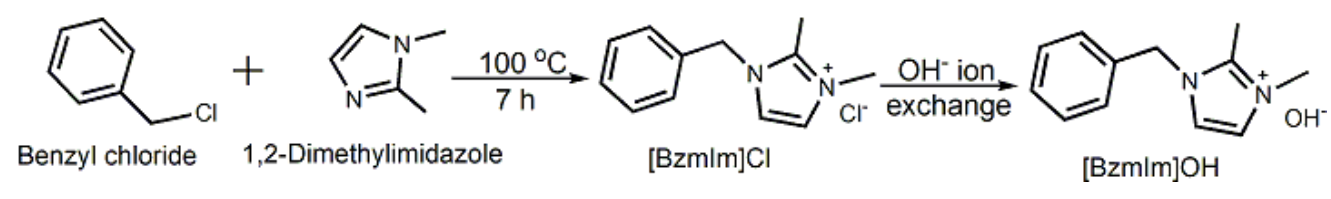

Scheme 1. Synthesis pathway of [bzmIm]Cl before converting to [bzmIm]OH via ion exchange.

\subsection{Synthesis of SAPO-5 Microporous Solids}

SAPO-5 was synthesized as follows: Firstly, aluminum isopropoxide $(3.2260 \mathrm{~g}, 98 \%$, Acros), [bzmIm] OH solution (26.2753 g), and distilled water (5.8279 g) were mixed and stirred (500 rpm) for $40 \mathrm{~min}$. Then, phosphoric acid (4.4615 g, 85\%, Merck) was slowly added into the slurry dropwise where the addition process took about $15 \mathrm{~min}$ to complete. HS-40 colloidal silica ( $0.5464 \mathrm{~g}$, Sigma-Aldrich) was successively added, forming a hydrogel with a final chemical composition of $1 \mathrm{Al}_{2} \mathrm{O}_{3}: 2.5 \mathrm{P}_{2} \mathrm{O}_{5}: 2.5[\mathrm{bzmIm}]_{2} \mathrm{O}: 0.47 \mathrm{SiO}_{2}: 180 \mathrm{H}_{2} \mathrm{O}$. The resulting precursor was loaded into a $50 \mathrm{~mL}$ Teflon-lined stainless-steel autoclave, sealed 
tightly, and heated at $150{ }^{\circ} \mathrm{C}$ for $10 \mathrm{~h}$. The obtained solid product, denoted as $\mathrm{SH}-4$, was purified with distilled water via centrifugation $(9000 \mathrm{rpm}, 10 \mathrm{~min}$ ) until $\mathrm{pH} 7$ prior to freezedrying. For the study of the effects of various synthesis parameters, a similar procedure was applied where the chemical composition of precursor hydrogels (SH1-SH20) and their respective synthesis conditions are summarized in Table 1.

Table 1. Chemical composition and crystallization conditions of SH1-SH20 hydrogels together with the products obtained after altering the individual synthesis parameter.

\begin{tabular}{|c|c|c|c|c|c|c|c|c|c|c|}
\hline \multirow{2}{*}{$\begin{array}{l}\text { Synthesis } \\
\text { Parameters }\end{array}$} & \multirow{2}{*}{ Samples } & \multicolumn{5}{|c|}{ Gel Molar Composition } & \multirow{2}{*}{$\mathrm{T}\left({ }^{\circ} \mathrm{C}\right)$} & \multirow{2}{*}{$t(h)$} & \multirow{2}{*}{$\begin{array}{l}\mathrm{Si} /(\mathbf{P}+\mathrm{Al}+ \\
\text { Si) Ratio* }\end{array}$} & \multirow{2}{*}{ Products ${ }^{+}$} \\
\hline & & $\mathrm{Al}_{2} \mathrm{O}_{3}$ & $\mathrm{P}_{2} \mathrm{O}_{5}$ & {$[\text { bzmIm }]_{2} \mathrm{O}$} & $\mathrm{SiO}_{2}$ & $\mathrm{H}_{2} \mathrm{O}$ & & & & \\
\hline \multirow{5}{*}{ Time } & SH1 & \multirow{5}{*}{1} & \multirow{5}{*}{2.5} & \multirow{5}{*}{2.5} & \multirow{5}{*}{0.47} & \multirow{5}{*}{180} & \multirow{5}{*}{150} & 2 & 0.008 & Amor. \\
\hline & $\mathrm{SH} 2$ & & & & & & & 4 & 0.021 & Amor. \\
\hline & $\mathrm{SH} 3$ & & & & & & & 8 & 0.051 & Amor. + AFI \\
\hline & $\mathrm{SH} 4$ & & & & & & & 10 & 0.056 & AFI \\
\hline & SH5 & & & & & & & 14 & 0.057 & $\mathrm{AFI}+\mathrm{AFO}$ \\
\hline \multirow{4}{*}{$\mathrm{P}_{2} \mathrm{O}_{5}$} & SH6 & \multirow{4}{*}{1} & 2.0 & \multirow{4}{*}{2.5} & \multirow{4}{*}{0.47} & \multirow{4}{*}{180} & \multirow{4}{*}{150} & \multirow{4}{*}{10} & - & No solid \\
\hline & SH4 & & 2.5 & & & & & & 0.056 & AFI \\
\hline & SH7 & & 3.0 & & & & & & 0.062 & AFI \\
\hline & SH8 & & 3.5 & & & & & & 0.067 & AFI + cristobalite \\
\hline \multirow{4}{*}{$\underset{/[\mathrm{bzmIm}]_{2} \mathrm{O}}{\mathrm{P}_{2} \mathrm{O}_{5}}$} & SH9 & \multirow{4}{*}{1} & 1.5 & 1.5 & \multirow{4}{*}{0.47} & \multirow{4}{*}{180} & \multirow{4}{*}{150} & \multirow{4}{*}{10} & 0.059 & AFI \\
\hline & SH10 & & 2.0 & 2.0 & & & & & 0.057 & AFI \\
\hline & $\mathrm{SH} 4$ & & 2.5 & 2.5 & & & & & 0.056 & AFI \\
\hline & SH11 & & 3.0 & 3.0 & & & & & 0.053 & AFI \\
\hline \multirow{4}{*}{$\mathrm{H}_{2} \mathrm{O}$} & SH12 & \multirow{4}{*}{1} & \multirow{4}{*}{2.5} & & & 135 & & & 0.053 & Amor. + AFI \\
\hline & $\mathrm{SH} 4$ & & & 25 & 047 & 180 & 150 & 10 & 0.056 & AFI \\
\hline & SH13 & & & 2.3 & 0.47 & 225 & 100 & 10 & 0.057 & AFI \\
\hline & SH14 & & & & & 270 & & & 0.061 & Tridymite \\
\hline & SH15 & & & & 0 & & & & 0 & AFI (AlPO-5) \\
\hline $\mathrm{SiO}$ & SH16 & 1 & 25 & 25 & 0.23 & 180 & 150 & 10 & 0.031 & AFI \\
\hline $\mathrm{SIO}_{2}$ & $\mathrm{SH} 4$ & 1 & 2.5 & 2.5 & 0.47 & 180 & 150 & 10 & 0.056 & AFI \\
\hline & SH17 & & & & 0.7 & & & & 0.061 & AFI \\
\hline & SH18 & & & & & & 100 & & 0.010 & Amor. \\
\hline Temporature & SH19 & & & & & & 120 & & 0.021 & AFI \\
\hline lemperature & SH4 & 1 & 2.5 & 2.5 & 0.47 & 180 & 150 & 10 & 0.056 & AFI \\
\hline & SH20 & & & & & & 200 & & 0.064 & Tridymite \\
\hline
\end{tabular}

* Determined by XRF. ${ }^{\dagger}$ Amor. $=$ Amorphous; AFI = SAPO-5; AFO = SAPO-41.

\subsection{Characterization}

The crystallinity and phase composition of powder samples were analyzed using a Bruker Advance D8 XRD diffractometer with $\mathrm{Cu} \mathrm{K} \alpha$ radiation $(\lambda=0.15418 \mathrm{~nm}, 40 \mathrm{kV}$, $10 \mathrm{~mA}$, step size $=0.02^{\circ}$, scan speed $=0.2^{\circ} / \mathrm{min}$ ). The morphological properties of samples were studied using a Leo Supra 50VP field emission scanning electron microscope (FESEM) operated at $20 \mathrm{kV}$. The particle size distributions (PSDs) of samples were analyzed and plotted using the ImageJ (1.8.0_172) software by randomly measuring 100 particles of the FESEM images obtained from different spots. The elemental compositions of the solid samples were analyzed using an XRF spectrometer (Phillips X'Unique).

\section{Results and Discussion}

\subsection{Effect of Crystallization Time}

$\mathrm{SH} 1, \mathrm{SH} 2, \mathrm{SH} 3, \mathrm{SH} 4$, and $\mathrm{SH} 5$ samples with a composition of $1 \mathrm{Al}_{2} \mathrm{O}_{3}: 2.5 \mathrm{P}_{2} \mathrm{O}_{5}: 2.5$ [bzmIm] $]_{2} \mathrm{O}: 0.47 \mathrm{SiO}_{2}: 180 \mathrm{H}_{2} \mathrm{O}$ were heated at $150{ }^{\circ} \mathrm{C}$ for $2,4,8,10$, and $14 \mathrm{~h}$, respectively (Table 1). According to XRD analysis, the $\mathrm{SH} 1$ and $\mathrm{SH} 2$ samples were amorphous with no significant diffraction peaks and a broad hump observed at $2 \theta \approx 20^{\circ}-35^{\circ}$ (intensity 
of the hump was low in relative to the other crystalline samples), indicating the phase reorganization between amorphous particles, forming a secondary and more reactive amorphous entity (Figure 1) [16]. When the time was extended to $8 \mathrm{~h}$, the XRD peaks due to SAPO-5 started to appear at $2 \theta=7.3^{\circ}[100], 14.8^{\circ}[200], 19.6^{\circ}$ [210], and $25.8^{\circ}$ [202], revealing that SAPO-5 nuclei started to form in the amorphous bulk solid [17]. After $10 \mathrm{~h}$ of heating, the amorphous solid was fully converted into crystalline SAPO- 5 solid and further crystal growth of SAPO- 5 crystals was observed after $14 \mathrm{~h}$, as indicated by the narrower and more intense peaks of crystalline AFI microporous framework. However, a phase transformation of SAPO-5 (AFI framework) into SAPO-41 (AFO framework) was also observed with prolonged crystallization time. The XRD analysis thus demonstrated that the formation evolution of SAPO-5 underwent four distinctive stages, namely induction, nucleation, crystallization and Ostwald ripening, which will be described in detail in Section 3.7.

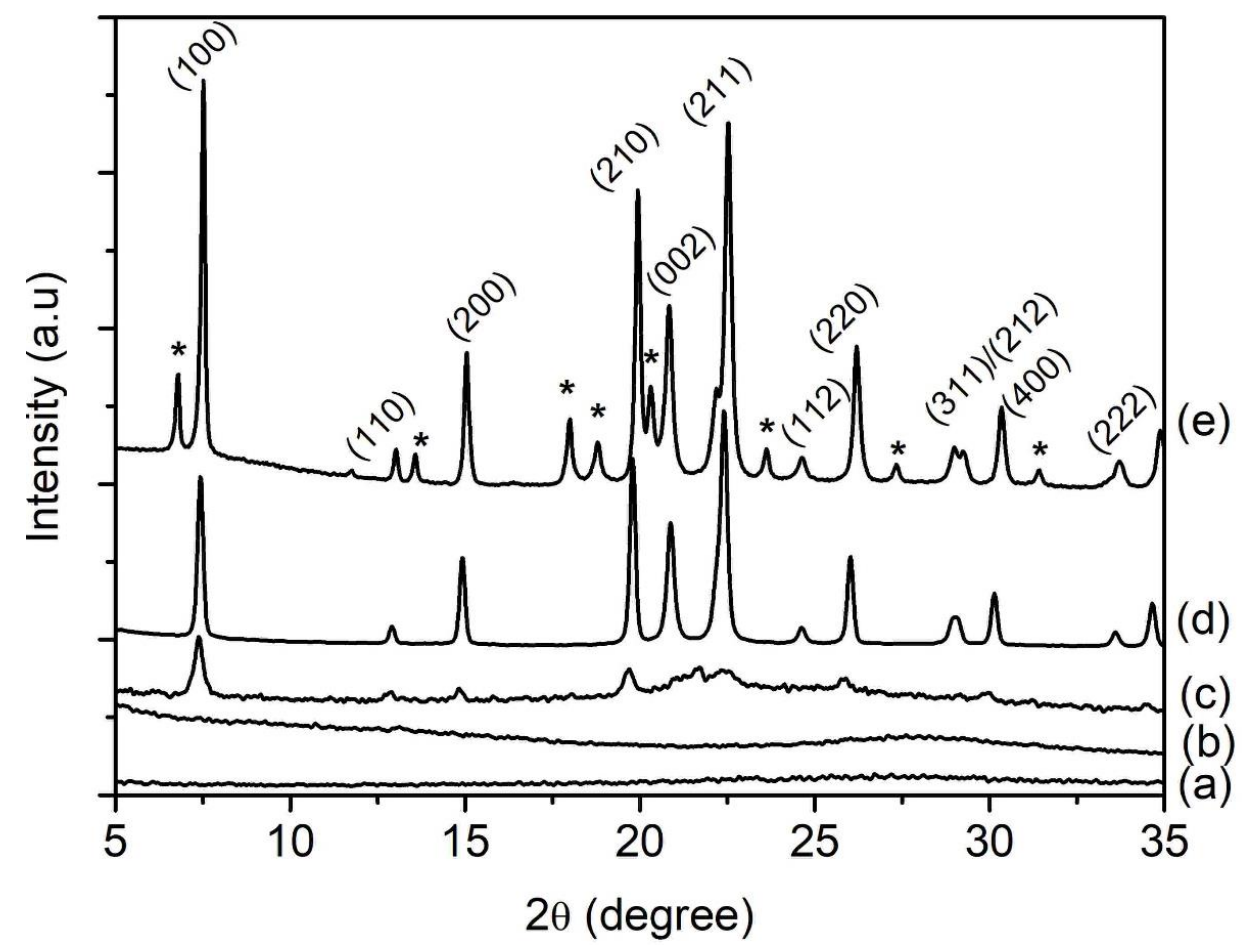

Figure 1. XRD patterns of (a) SH1, (b) SH2, (c) SH3, (d) $\mathrm{SH} 4$ and (e) $\mathrm{SH} 5$ samples prepared with a molar composition of $1 \mathrm{Al}_{2} \mathrm{O}_{3}: 2.5 \mathrm{P}_{2} \mathrm{O}_{5}: 0.47 \mathrm{SiO}_{2}: 2.5[\mathrm{bzmIm}]_{2} \mathrm{O}: 180 \mathrm{H}_{2} \mathrm{O}$ and heated at $150{ }^{\circ} \mathrm{C}$ for $2 \mathrm{~h}$, $4 \mathrm{~h}, 8 \mathrm{~h}, 10 \mathrm{~h}$ and $14 \mathrm{~h}$, respectively. Asterisks denote the presence of SAPO-41 phase.

The FESEM images of SH1, SH3, SH4 and SH5 were also captured to study the crystallization process of SAPO-5. SH1 sample was formed by the agglomerated and irregular-shaped particles, confirming the amorphous nature of this sample (Figure 2A(a)). The particle size distribution (PSD) of SH1 was plotted and a monomodal curve centered at $120 \mathrm{~nm}$ was obtained (Figure 2B(a)). This peak was shifted to larger particle sizes after $8 \mathrm{~h}$, indicating amorphous phase reorganization as proven by the XRD analysis (Figure 2B(b)). In addition, another PSD centered at $500 \mathrm{~nm}$ was also observed, thus showing the presence of two different phases in SH3 sample. As seen, $\mathrm{SH} 3$ sample was a semi-crystalline solid with the SAPO-5 crystals of hexagonal prism shape growing on the amorphous entities (Figure 2A(b)). At $10 \mathrm{~h}$, the small amorphous solids disappeared, and the SAPO- 5 crystals grew further (mean size: $650 \mathrm{~nm}$ ), as confirmed by the FESEM and PSD studies (Figure 2A(c),B(c)). Successive phase transformation of SAPO-5 into SAPO-41 was also observed in $\mathrm{SH} 5$ after $14 \mathrm{~h}$ of heating where larger secondary particles made by agglomerated primary crystals of SAPO- 5 and SAPO-41 (both in hexagonal prism shape $[18,19]$ ) were detected (Figure $2 A(d), B(d)$ ). 

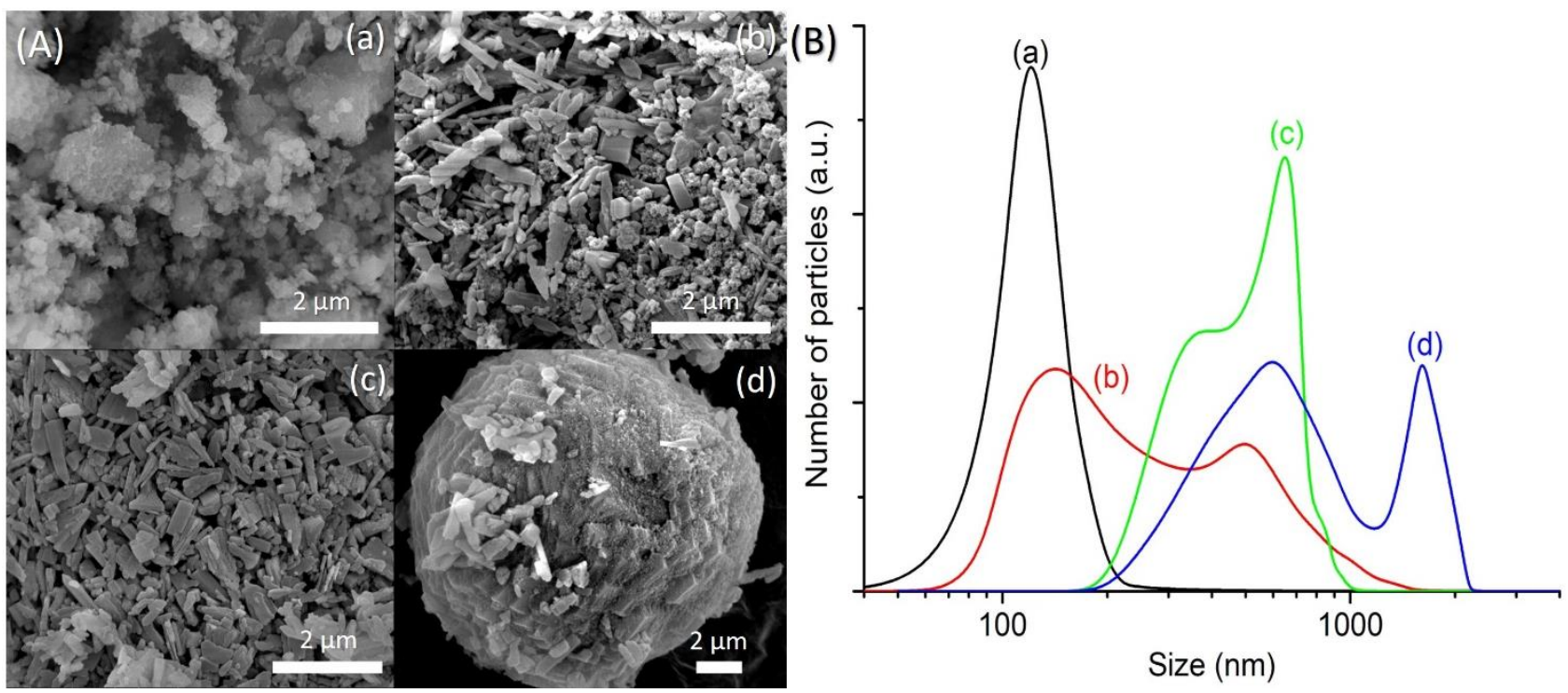

Figure 2. (A) Field emission scanning electron microscope (FESEM) images and (B) particle size distributions of (a) SH1, (b) SH3, (c) SH4 and (d) SH5 samples after heating at $150^{\circ} \mathrm{C}$ for $2 \mathrm{~h}, 8 \mathrm{~h}, 10 \mathrm{~h}$, and $14 \mathrm{~h}$, respectively.

\subsection{Effect of $\mathrm{P}_{2} \mathrm{O}_{5} / \mathrm{Al}_{2} \mathrm{O}_{3}$ Molar Ratio}

The amount of $\mathrm{P}_{2} \mathrm{O}_{5}$ and $\mathrm{Al}_{2} \mathrm{O}_{3}$ in the initial hydrogel is important since both species are the basic elements for building the AFI framework. Hence, the effects of $\mathrm{P}_{2} \mathrm{O}_{5} / \mathrm{Al}_{2} \mathrm{O}_{3}$ ratio were studied using a precursor hydrogel of $1 \mathrm{Al}_{2} \mathrm{O}_{3}: w \mathrm{P}_{2} \mathrm{O}_{5}: 2.5[\mathrm{bzmIm}]_{2} \mathrm{O}: 180 \mathrm{H}_{2} \mathrm{O}: 0.47 \mathrm{SiO}_{2}$, where $w$ varied from 2.0 to 3.5. When $w=2.0$ (SH6), no solid was precipitated after hydrothermal treatment at $150{ }^{\circ} \mathrm{C}$ for $10 \mathrm{~h}$, which could be explained by the high alkalinity of the hydrogel ( $\mathrm{pH} 10.2)$ as the amount of $\mathrm{H}_{3} \mathrm{PO}_{4}$ added was much lower than that of alkaline [bzmIm] OH introduced. Hence, the solid product formed tended to re-dissolve back into the mother liquor [20]. When the $\mathrm{P}_{2} \mathrm{O}_{5} / \mathrm{Al}_{2} \mathrm{O}_{3}$ ratio increased to $w=2.5$ (SH4), the alkalinity of the reaction mixture reduced significantly to nearly neutral $(\mathrm{pH} 7.5)$ and a solid product was successfully precipitated. The solid was found to be SAPO-5 crystalline solid based on the XRD observation (Figure 3). In addition, the SAPO-5 solids exhibited hexagonal prism shape with an average crystal size of $650 \mathrm{~nm}$ (Figure $4 \mathrm{~A}(\mathrm{a}), \mathrm{B}(\mathrm{a})$ )).

Further increasing the $\mathrm{P}_{2} \mathrm{O}_{5} / \mathrm{Al}_{2} \mathrm{O}_{3}$ ratio to $w=3$ induced crystal growth where it could be confirmed by the narrower and more intense XRD peaks in HS7 sample. The XRD observation was also supported by the FESEM study where large spherical particles formed by intergrown SAPO- 5 crystals were captured (Figure 4B(b)). Meanwhile, partial phase transformation of SAPO-5 into dense cristobalite phase was observed with further increasing the $\mathrm{P}_{2} \mathrm{O}_{5} / \mathrm{Al}_{2} \mathrm{O}_{3}$ ratio $(w=3.5, \mathrm{pH} 4.8)$, where an evolution change of morphology to intergrown grain secondary particles was also detected (Figures 3 and 4). Obviously, an increase in $\mathrm{P}_{2} \mathrm{O}_{5}$ content had a profound effect on the crystallization profile of SAPO-5 [21]. Whether the cristobalite phase is purely composed of pure silica, aluminophosphate, or silicoaluminophosphate could not be ascertained at this stage. 


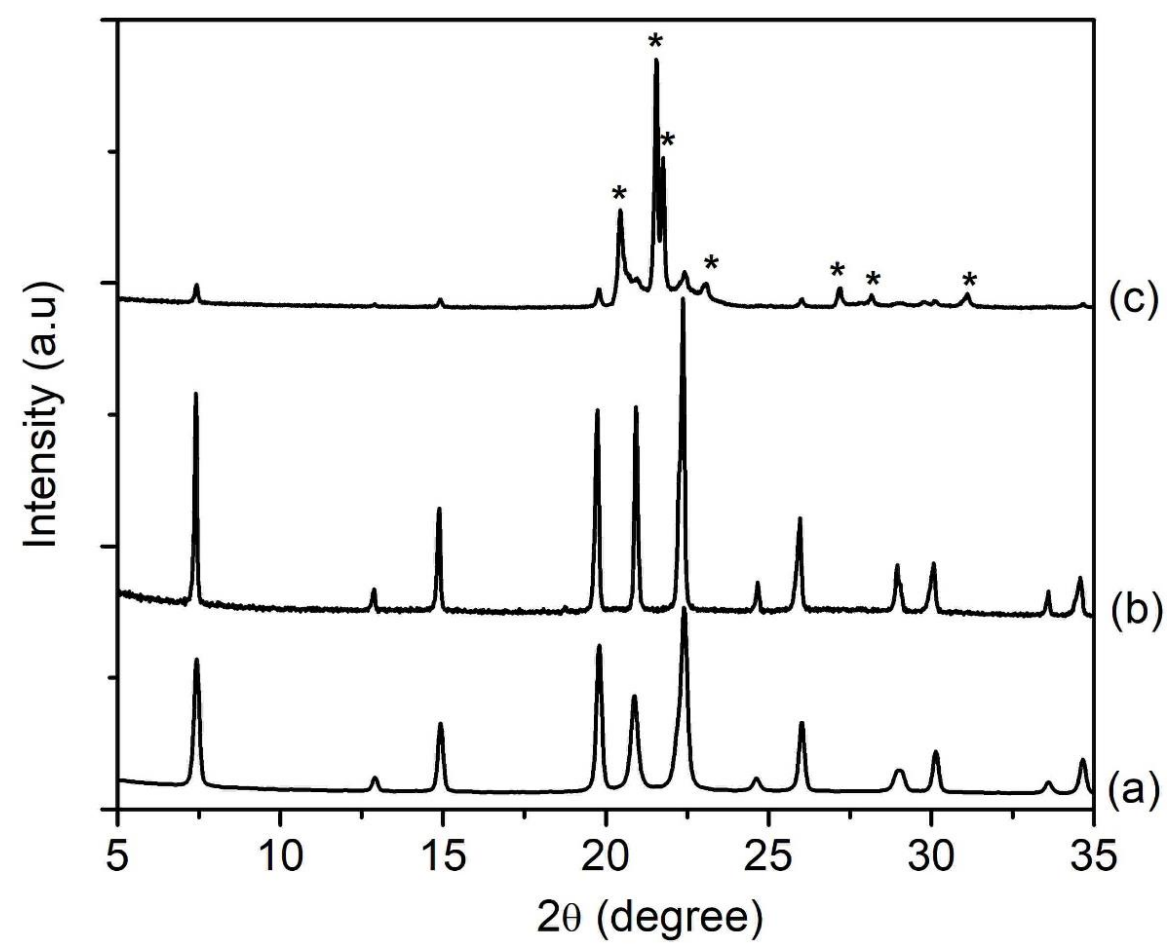

Figure 3. XRD patterns of (a) SH4 $(w=2.5)$, (b) SH7 $(w=3.0)$ and (c) SH8 $(w=3.5)$ solids where the solid products were prepared using precursor hydrogels with a molar composition of $1 \mathrm{Al}_{2} \mathrm{O}_{3}: w \mathrm{P}_{2} \mathrm{O}_{5}: 2.5[\mathrm{bzmIm}]_{2} \mathrm{O}: 180 \mathrm{H}_{2} \mathrm{O}: 0.47 \mathrm{SiO}_{2}$ heated at $150{ }^{\circ} \mathrm{C}$ for $10 \mathrm{~h}$. The asterisks show the presence of cristobalite dense phase.
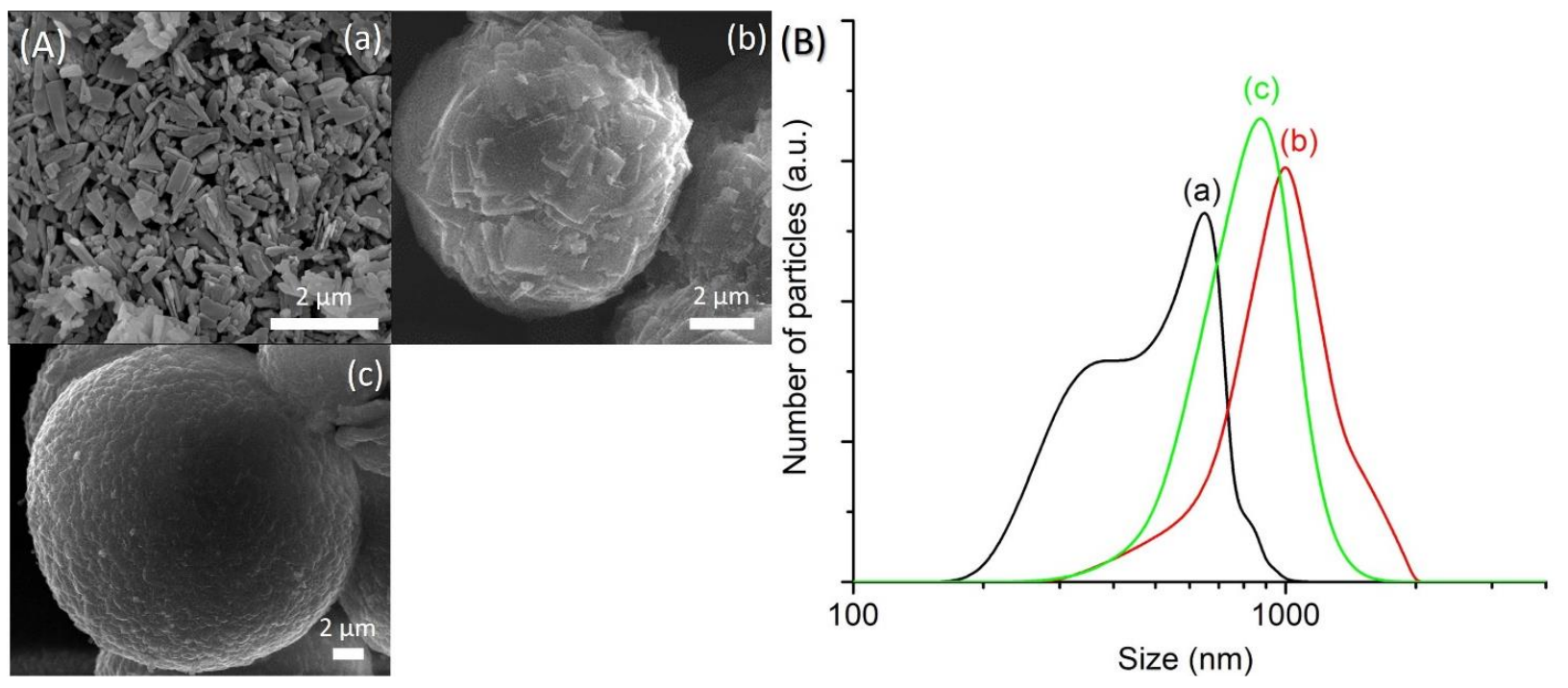

Figure 4. (A) FESEM images and (B) particle size distributions of (a) SH4 ( $w=2.5)$, (b) SH7 ( $w=3.0)$ and (c) SH8 $(w=3.5)$ where the solid products were prepared using precursor hydrogels with a molar composition of $1 \mathrm{Al}_{2} \mathrm{O}_{3}: w \mathrm{P}_{2} \mathrm{O}_{5}: 2.5[\mathrm{bzmIm}]_{2} \mathrm{O}: 180 \mathrm{H}_{2} \mathrm{O}: 0.47 \mathrm{SiO}_{2}$ heated at $150{ }^{\circ} \mathrm{C}$ for $10 \mathrm{~h}$.

\subsection{Effect of $[\mathrm{bzmIm}]_{2} \mathrm{O} / \mathrm{P}_{2} \mathrm{O}_{5}$ Molar Ratio}

An equimolar amount of [bzmIm $]_{2} \mathrm{O}$ and $\mathrm{P}_{2} \mathrm{O}_{5}(x)$ was used to control the $\mathrm{pH}$ of precursor hydrogel since the crystallization of SAPO-5 is more favorable at nearly neutral $\mathrm{pH}$ condition, as observed in Section 3.2. The $\mathrm{pH}$ values of the hydrogels of $\mathrm{SH} 9(x=1.5)$, SH10 $(x=2.0)$, SH4 $(x=2.5)$ and SH11 $(x=3.0)$ were measured to be $6.42,6.15,6.07$ and 6.14 , respectively. As seen, all samples successfully produced SAPO- 5 crystalline phase with no impurity but with different XRD peak widths, suggesting different crystal sizes 
(Figure 5). This could also be confirmed by the PSD analysis that the mean crystal size was reduced from $1.5 \mu \mathrm{m}$ to $1.1 \mu \mathrm{m}, 650 \mathrm{~nm}$ and $380 \mathrm{~nm}$ when the $x$ value increased from 1.5 to 2.0, 2.5 and 3.0, respectively (Figure 6B). Furthermore, the morphology of SAPO-5 crystals was also changed from hexagonal plate shape to hexagonal prism form when increasing the $x$ values (Figure 6A).

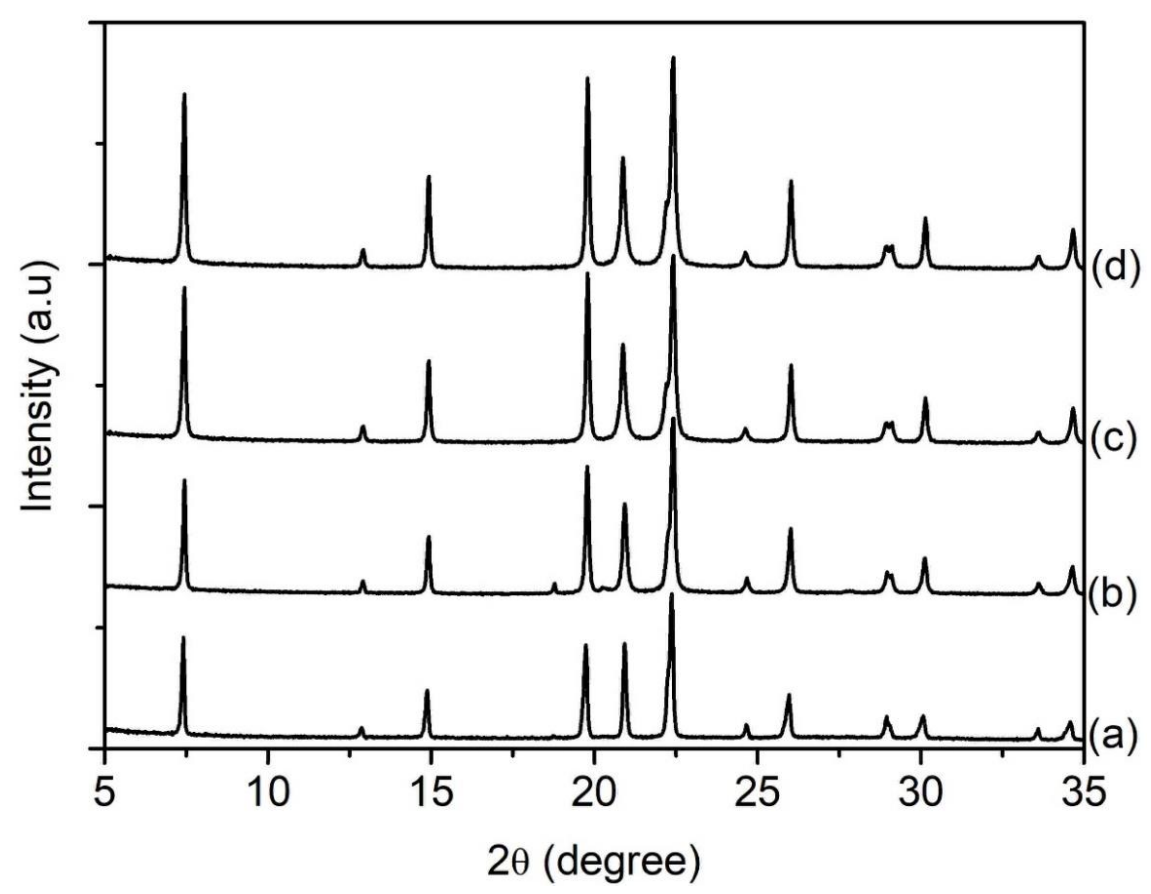

Figure 5. XRD patterns of (a) SH9 (x=1.5), (b) SH10 (x=2.0), (c) SH4 (x=2.5) and (d) SH11 $(x=3.0)$ where the solid products were prepared using precursor hydrogels with a molar composition of $1 \mathrm{Al}_{2} \mathrm{O}_{3}: x \mathrm{P}_{2} \mathrm{O}_{5}: x[\text { bzmIm }]_{2} \mathrm{O}: 180 \mathrm{H}_{2} \mathrm{O}: 0.47 \mathrm{SiO}_{2}$ at $150{ }^{\circ} \mathrm{C}$ for $10 \mathrm{~h}$.
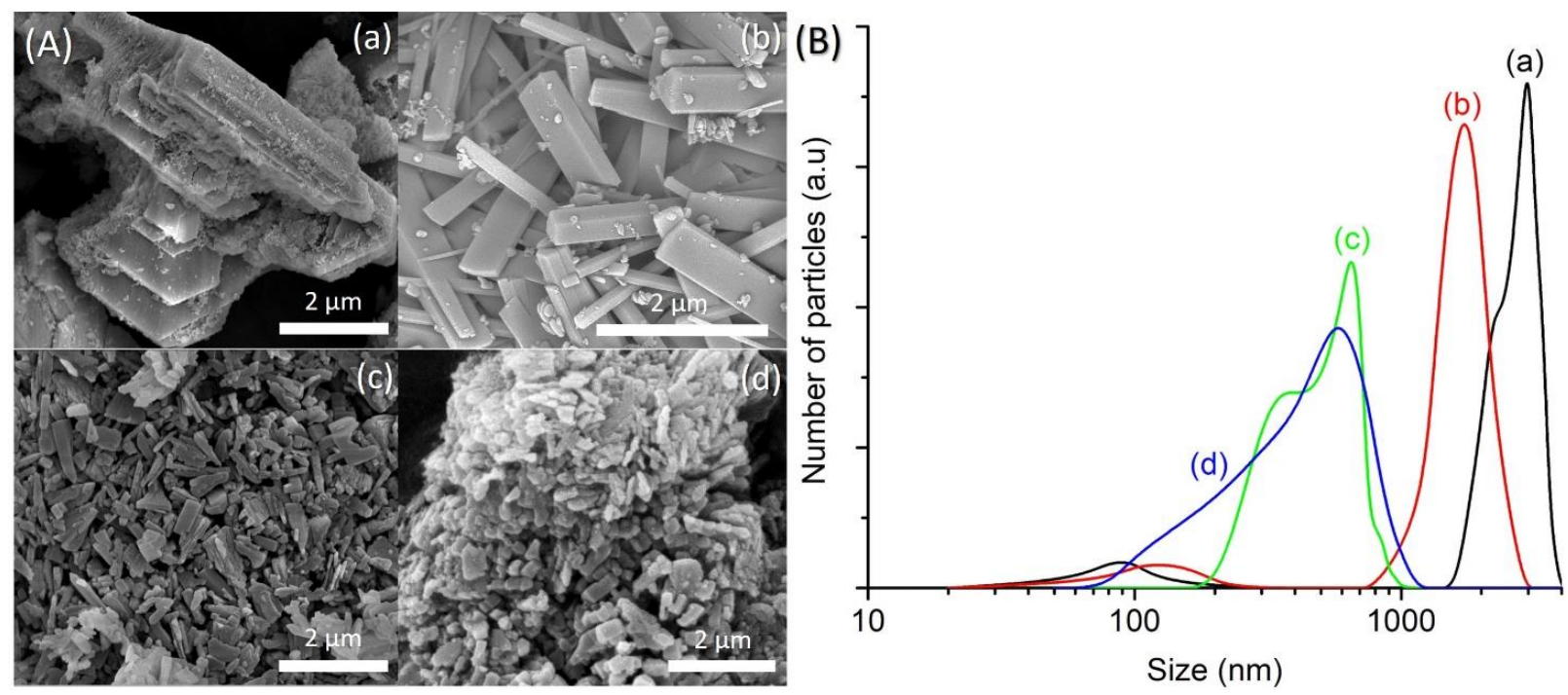

Figure 6. (A) FESEM images and (B) particle size distributions of (a) SH9 ( $x=1.5)$, (b) SH10 ( $x=2.0)$, (c) SH4 ( $x=2.5)$ and (d) SH11 ( $x=3.0)$ where the solid products were prepared using precursor hydrogels with a molar composition of $1 \mathrm{Al}_{2} \mathrm{O}_{3}: x \mathrm{P}_{2} \mathrm{O}_{5}: x[\mathrm{bzmIm}]_{2} \mathrm{O}: 180 \mathrm{H}_{2} \mathrm{O}: 0.47 \mathrm{SiO}_{2}$ at $150{ }^{\circ} \mathrm{C}$ for $10 \mathrm{~h}$.

It is known that the crystal size of zeolites can be predetermined from the extent of nuclei present in the precursor hydrogel. On account of this, an increase in the alkalinity of the hydrogel during the addition of a large amount of organic template, followed by adding 
$\mathrm{H}_{3} \mathrm{PO}_{4}$ to reach nearly neutral $\mathrm{pH}$, promotes low polymerization of aluminate, phosphate and silicate species. As a result, a large number of nuclei are formed under supersaturation condition $[14,22,23]$. For this reason, small-sized SAPO- 5 crystals are produced when the $x$ value increases.

\subsection{Effect of $\mathrm{H}_{2} \mathrm{O}$ Content}

The amount of water present in the precursor hydrogel determines the concentration of reactants, which affects the properties of the final solid product (e.g., phase purity, crystallinity, size, morphology) [24]. In respect to this, four samples of different water contents (SH12, SH4, SH13 and SH14) were prepared by heating the precursor hydrogels with a molar composition of $1 \mathrm{Al}_{2} \mathrm{O}_{3}: 2.5 \mathrm{P}_{2} \mathrm{O}_{5}: 2.5[\mathrm{bzmIm}]_{2} \mathrm{O}: y \mathrm{H}_{2} \mathrm{O}: 0.47 \mathrm{SiO}_{2}(y=135,180$, 225 and 270) at $150{ }^{\circ} \mathrm{C}$ for $10 \mathrm{~h}$, respectively. It was observed that the crystallinity, crystal size, and purity of SAPO- 5 could be controlled by simply tuning the water content. The SH12, which contained the lowest amount of water $(y=135)$, showed very weak XRD peaks of AFI phase at $2 \theta=12.89^{\circ}$ [110], 20.83 ${ }^{\circ}$ [002], 25.90 [220], and 29.00 [311] (Figure 7a). Thus, the sample was a semi-crystalline nano-solid (mean size of $141 \mathrm{~nm}$ ) with a nondistinctive shape (Figure $8 \mathrm{~A}(\mathrm{a}), \mathrm{B}(\mathrm{a})$ ). The crystallinity of SAPO- 5 increased when the water content was increased to $y=180$ (SH4, Figure $7 \mathrm{~b}$ ). No amorphous solid was detected under microscopy investigation. Instead, it contained crystals with a hexagonal prism shape (mean size of $650 \mathrm{~nm}$ ), viz. a typical morphological feature for an AFI-type material (Figure $8 \mathrm{~A}(\mathrm{~b}), \mathrm{B}(\mathrm{b}))[9,25]$. The crystallinity and crystal size further increased when the water contents were increased to $y=225$ and 270 where co-crystallization of tridymite as minor dense phase was observed in the latter sample (Figures 7 and 8A). Furthermore, the SAPO- 5 crystals with distinguished bimodal size distribution were also shown, indicating the important role of water in the crystallization of SAPO-5 (Figure 8B).

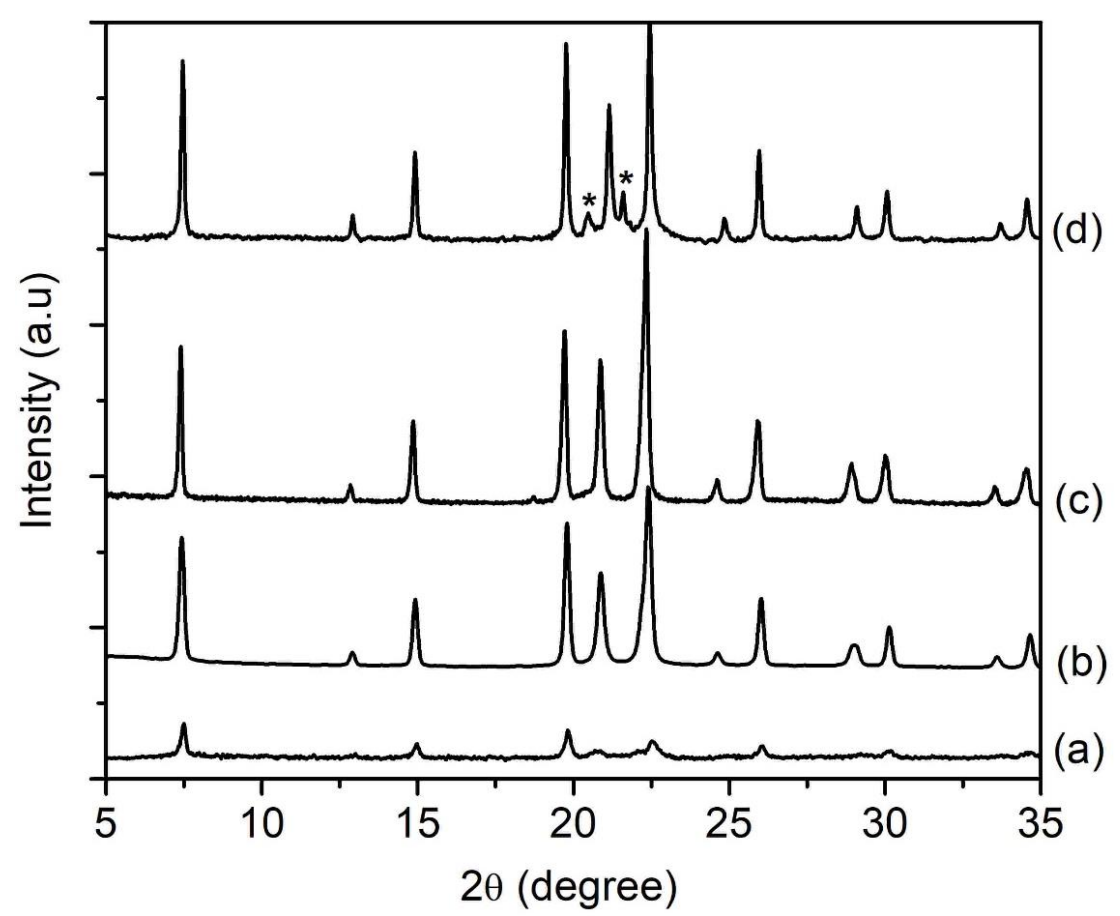

Figure 7. XRD patterns of (a) SH12 ( $y=135),(\mathbf{b})$ SH4 $(y=180),(\mathbf{c})$ SH13 $(y=225)$ and (d) SH14 $(y=270)$ solid products, which were prepared using precursor hydrogels with a molar composition of $1 \mathrm{Al}_{2} \mathrm{O}_{3}: 2.5 \mathrm{P}_{2} \mathrm{O}_{5}: 2.5[\mathrm{bzmIm}]_{2} \mathrm{O}: y \mathrm{H}_{2} \mathrm{O}: 0.47 \mathrm{SiO}_{2}$ heated at $150{ }^{\circ} \mathrm{C}$ for $10 \mathrm{~h}$. The asterisks show the presence of tridymite dense phase. 

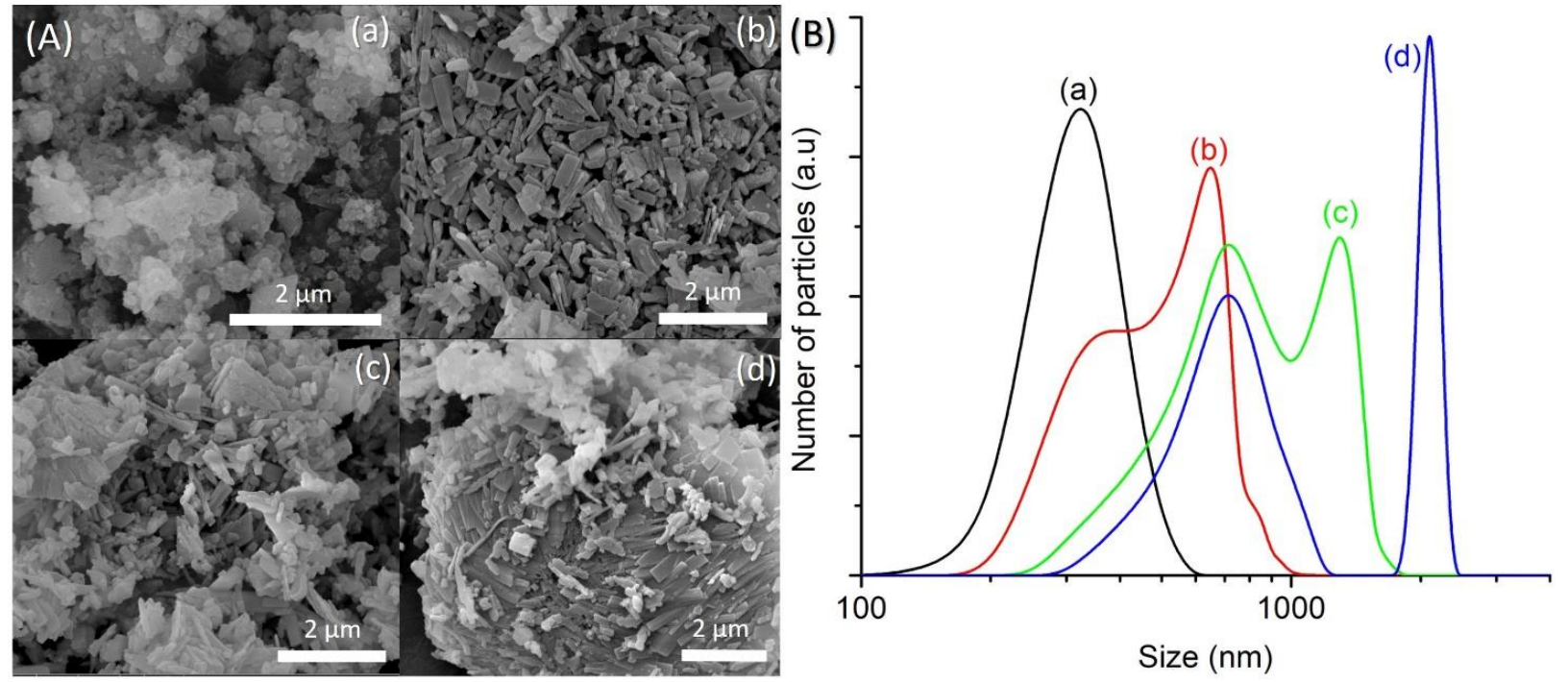

Figure 8. (A) FESEM images and (B) particle size distributions of (a) SH12 ( $y=135)$, (b) SH4 ( $y=180),(\mathbf{c})$ SH13 ( $y=225)$ and $(\mathbf{d}) \mathrm{SH} 14(y=270)$ solid products, which were prepared using precursor hydrogels with a molar composition of $1 \mathrm{Al}_{2} \mathrm{O}_{3}: 2.5 \mathrm{P}_{2} \mathrm{O}_{5}: 2.5[\mathrm{bzmIm}]_{2} \mathrm{O}: y \mathrm{H}_{2} \mathrm{O}: 0.47 \mathrm{SiO}_{2}$ heated at $150{ }^{\circ} \mathrm{C}$ for $10 \mathrm{~h}$.

It is known that the supersaturation condition favors the formation of a large number of nuclei when the water content is reduced. Concurrently, the enhanced alkalinity of the precursor hydrogel induces low polymerization of aluminate, phosphate and silicate species, thus leading to the formation of smaller SAPO-5 crystals [26,27]. However, with increasing the water content, a less concentrated hydrogel with more acidic environment is prepared, and it tends to retard the nucleation process, which leads to the formation of larger-sized SAPO-5 crystals [28]. Furthermore, tridymite is also co-crystallized when increasing the water content because dense crystalline phases preferably crystallize under an acidic environment [29].

\subsection{Effect of $\mathrm{SiO}_{2} / \mathrm{Al}_{2} \mathrm{O}_{3}$ Molar Ratio}

In this study, the effects of silica content (expressed in $\mathrm{SiO}_{2} / \mathrm{Al}_{2} \mathrm{O}_{3}$ molar ratio) were studied considering the significance and high tendency of silicon atoms insertion into the parent AlPO- 5 during the crystallization process [30,31]. Hence, the hydrogels with a composition of $1 \mathrm{Al}_{2} \mathrm{O}_{3}: 2.5 \mathrm{P}_{2} \mathrm{O}_{5}: 2.5[\text { bzmIm }]_{2} \mathrm{O}: 180 \mathrm{H}_{2} \mathrm{O}: z \mathrm{SiO}_{2}$, where $z=0$ (SH15), 0.23 (SH16), 0.47 (SH4) and 0.70 (SH17), were prepared. The XRD patterns of the samples were recorded and shown in Figure 9. Without adding any $\mathrm{SiO}_{2}$, the so-called AlPO-5 sample (SH15) showed an XRD pattern that perfectly matched with the AFI structure (Figure 9a). The diffraction peaks were broad, indicating small crystallite size, and it could be confirmed from the FESEM image that showed secondary micron-sized particles with layered morphology formed by agglomerated nanocrystals (mean size of $170 \mathrm{~nm}$ ) (Figure $10 \mathrm{~A}(\mathrm{a}), \mathrm{B}(\mathrm{a}))$. The phase purity remained the same when the Si content was increased to $z=0.23,0.47$, and 0.7 , but a significant change in crystal size and morphology was observed (Figure $10 \mathrm{~A}(\mathrm{~b}-\mathrm{d})$ ). As seen, the SAPO- 5 crystals tended to grow in $c$-direction when more $\mathrm{Si}$ atoms were incorporated, forming hexagonal prism crystals with an elongated shape and intergrown structure. As a result, the mean particle size of SAPO-5 increased from $260 \mathrm{~nm}(z=0.23)$ to $650 \mathrm{~nm}(z=0.47)$ before reaching to $4.2 \mu \mathrm{m}(z=0.7)$ (Figure 10B(b-d)). 


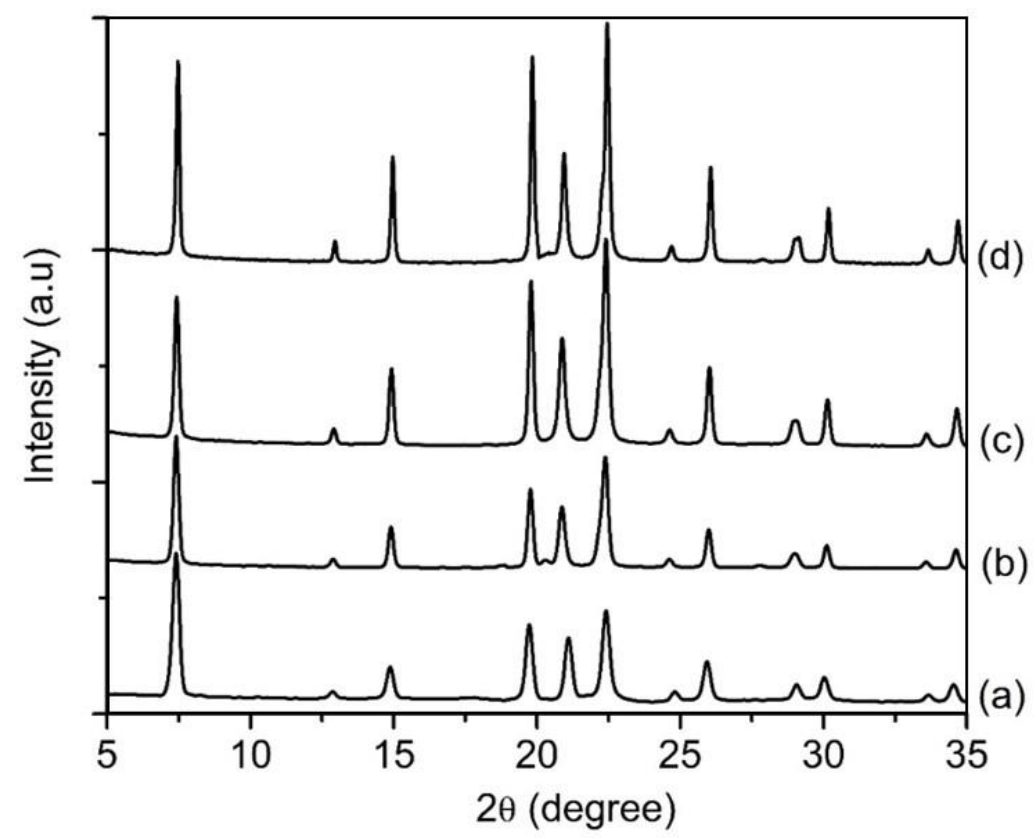

Figure 9. XRD patterns of (a) SH15 $(z=0)$, (b) SH16 ( $z=0.23)$, (c) SH4 ( $z=0.47)$ and (d) SH17 $(y=0.70)$ prepared with a molar composition of $1 \mathrm{Al}_{2} \mathrm{O}_{3}: 2.5 \mathrm{P}_{2} \mathrm{O}_{5}: 2.5[\text { bzmIm }]_{2} \mathrm{O}: 180 \mathrm{H}_{2} \mathrm{O}: 2 \mathrm{SiO}_{2}$ heated at $150{ }^{\circ} \mathrm{C}$ for $10 \mathrm{~h}$.
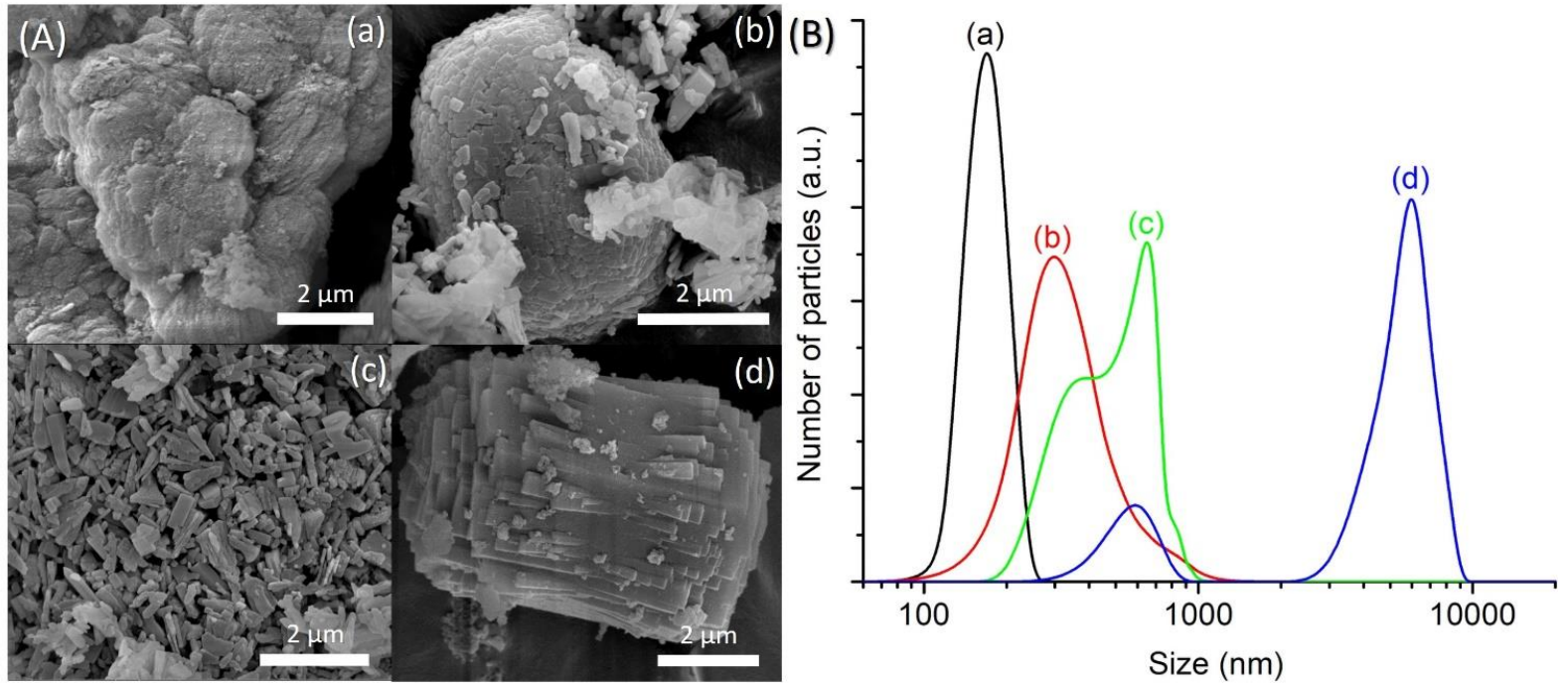

Figure 10. (A) FESEM images and (B) particle size distributions of (a) SH15 ( $z=0)$, (b) SH16 ( $z=0.23)$, (c) SH4 ( $z=0.47)$ and (d) $\mathrm{SH} 17(y=0.70)$ prepared with a molar composition of $1 \mathrm{Al}_{2} \mathrm{O}_{3}: 2.5 \mathrm{P}_{2} \mathrm{O}_{5}: 2.5[\mathrm{bzmIm}]_{2} \mathrm{O}: 180 \mathrm{H}_{2} \mathrm{O}: 2 \mathrm{SiO}_{2}$ heated at $150{ }^{\circ} \mathrm{C}$ for $10 \mathrm{~h}$.

\subsection{Effect of Heating Temperature}

The synthesis temperature affects the crystallization process of zeolite materials since it provides the energy needed for nucleation and crystal growth [24,32]. Hence, the hydrogel with a molar composition of $1 \mathrm{Al}_{2} \mathrm{O}_{3}: 2.5 \mathrm{P}_{2} \mathrm{O}_{5}: 2.5[\text { bzmIm] }]_{2} \mathrm{O}: 180 \mathrm{H}_{2} \mathrm{O}: 0.47 \mathrm{SiO}_{2}$ was hydrothermally heated at $100,120,150$ and $200{ }^{\circ} \mathrm{C}$ for $10 \mathrm{~h}$ (Table 1). The XRD patterns of the samples were recorded (Figure 11); while the FESEM images and particle size distribution were compiled in Figure 12A,B, respectively. The SH18 sample heated at $100{ }^{\circ} \mathrm{C}$ yielded an amorphous solid (mean size of $120 \mathrm{~nm}$ ) with a non-distinctive shape (Figures 11a and 12A(a),B(a)). Thus, it revealed that the rate of crystallization of SAPO-5 is slow at $100{ }^{\circ} \mathrm{C}$ due to insufficient energy supplied to the system [22]. Increasing the 
temperature to $120^{\circ} \mathrm{C}$ slightly accelerated the crystallization rate but the solid was partially converted to SAPO-5 as an amorphous hump was still observed at $2 \theta=20^{\circ}-30^{\circ}$ (Figure $11 \mathrm{~b}$ ). On the other hand, the morphology of the solids changed to a relatively hexagonal shape having a mean size of $374 \mathrm{~nm}$ (Figure $12 \mathrm{~A}(\mathrm{~b}), \mathrm{B}(\mathrm{b})$ ). At $150^{\circ} \mathrm{C}$, fully crystalline SAPO-5 was obtained (Figure 11c, Figure 12A(c)). Thus, this showed that the crystallization of SAPO-5 is a thermally activated process that requires energy to convert amorphous precursors into crystalline solids. Nevertheless, supplying excessive energy by increasing the temperature to $200{ }^{\circ} \mathrm{C}$ resulted in the crystallization of a tridymite dense phase. This is because SAPO- 5 is a metastable crystalline phase and it tends to transform into a denser phase at very high temperatures [33].

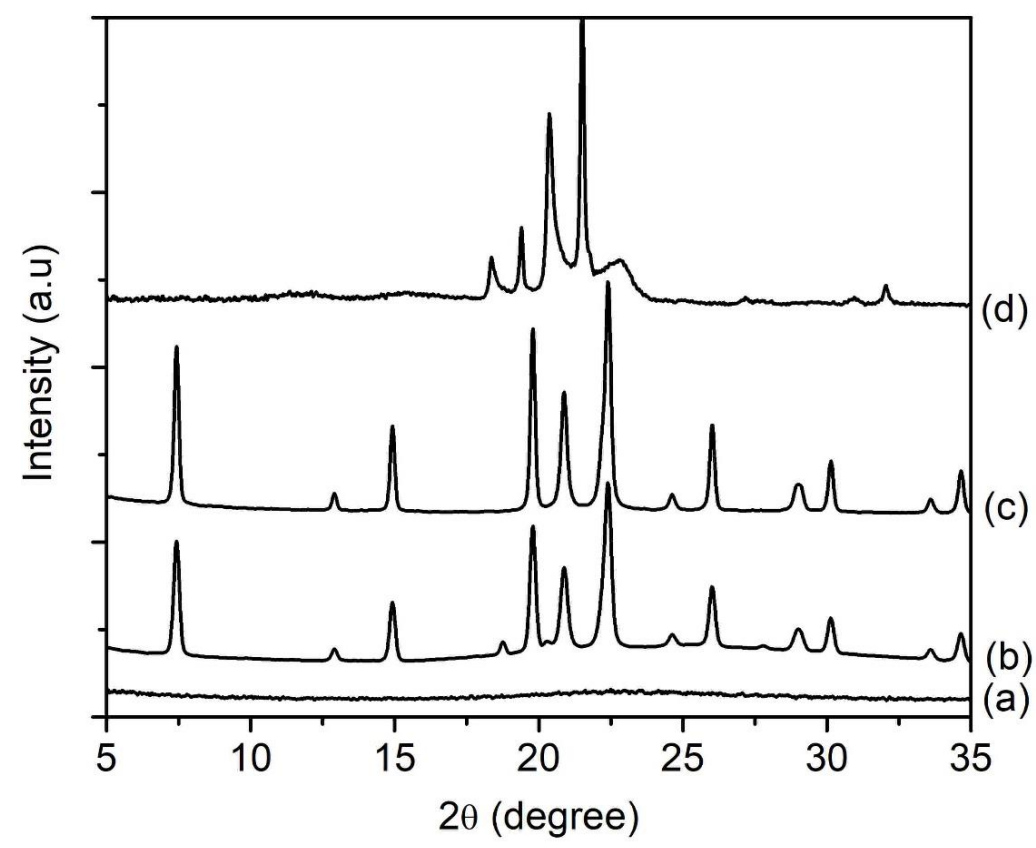

Figure 11. XRD patterns of (a) SH18, (b) SH19, (c) SH4 and (d) SH20 prepared with a molar composition of $1 \mathrm{Al}_{2} \mathrm{O}_{3}: 2.5 \mathrm{P}_{2} \mathrm{O}_{5}: 2.5[\mathrm{bzmIm}]_{2} \mathrm{O}: 180 \mathrm{H}_{2} \mathrm{O}: 0.47 \mathrm{SiO}_{2}$. The samples were heated at 100 , 120,150 and $200{ }^{\circ} \mathrm{C}$ for $10 \mathrm{~h}$, respectively.
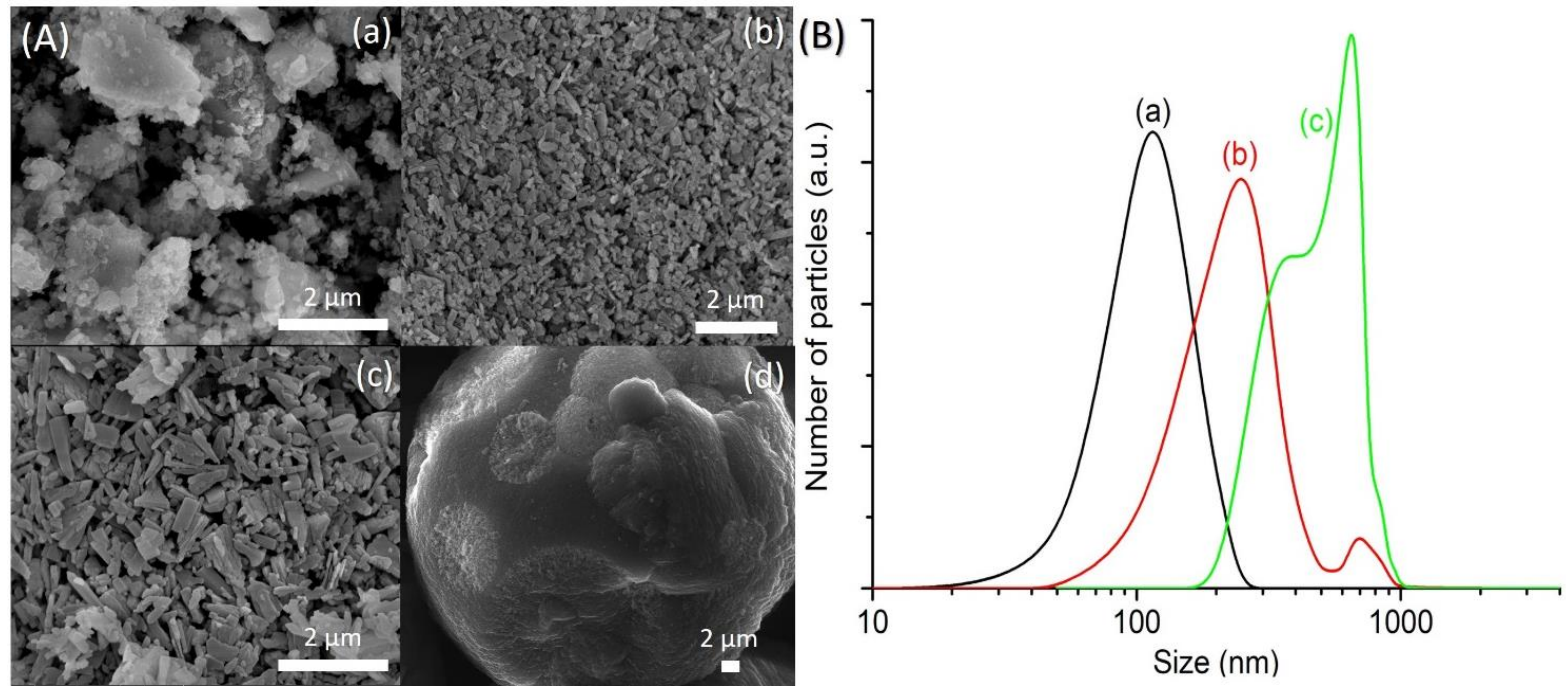

Figure 12. (A) SEM images and (B) particle size distributions of (a) SH18, (b) SH19, (c) SH4 and (d) SH20 prepared with a molar composition of $1 \mathrm{Al}_{2} \mathrm{O}_{3}: 2.5 \mathrm{P}_{2} \mathrm{O}_{5}: 2.5[\mathrm{bzmIm}]_{2} \mathrm{O}: 180 \mathrm{H}_{2} \mathrm{O}: 0.47 \mathrm{SiO}_{2}$. The samples were heated at 100, 120,150 and $200{ }^{\circ} \mathrm{C}$ for $10 \mathrm{~h}$, respectively. 


\subsection{Formation Pathway of SAPO-5 Crystals}

In general, the formation of SAPO- 5 crystals templated by [bzmIm] $\mathrm{OH}$ organic template involves four successive stages, namely, induction, nucleation, crystal growth, and Ostwald ripening (Figure 13). At the induction stage $\mathrm{Al}_{2} \mathrm{O}_{3}, \mathrm{P}_{2} \mathrm{O}_{5}$, and $\mathrm{SiO}_{2}$ precursors are hydrolyzed in the presence of $\mathrm{H}_{2} \mathrm{O}$, forming low molecular-weight monomers and dimers as primary building units (Step 1) [34]. Phase reorganization also occurs when longer chain oligomers are formed via polycondensation, as proven by the XRD analysis (Figure 1a,b). These oligomers tend to align and enfold around the $[\mathrm{bzmIm}]^{+}$molecules via restricted electrostatic interaction between the $[\mathrm{bzmIm}]^{+}$cation and the anionic silicoaluminophosphate species, forming an organic-inorganic intermediate species.
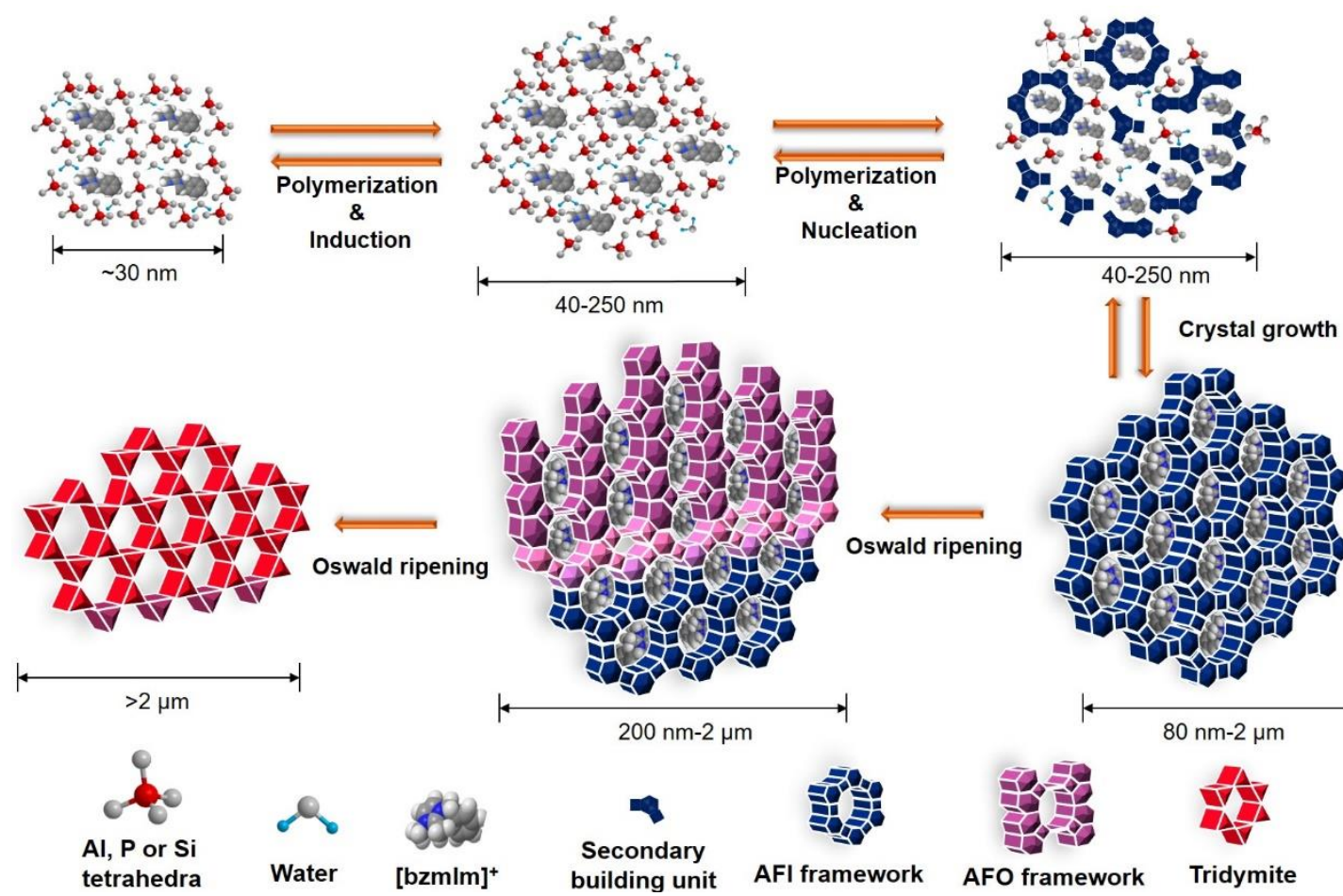

Figure 13. The hydrothermal crystallization pathway of SAPO-5 templating using [bzmIm]OH.

An equilibrium is established between the hydrolyzed intermediate species and the phase re-organized species, which later results in the nucleation stage (Step 2). During this phase, the formation of AFI framework by higher molecular-weight oligomers takes place [34]. The reaction equilibrium begins to shift to the direction of small nuclei with three-dimensional ordering so that they propagate into the eventual SAPO-5 framework structure. These nuclei serve as seeds or starting points for crystal growth in the secondary amorphous particles [35]. At this stage, the XRD and SEM analyses hardly detect the presence of SAPO- 5 crystalline phase.

Further prolonging the heating time results in the complete conversion of amorphous particles into SAPO-5 crystalline solids (Step 3). This phenomenon happens due to the fact that the amorphous particles are less thermodynamically stable in the mother liquor and they tend to re-dissolve or be consumed as nutrients for further crystal growth [36].

The last stage involves Ostwald ripening, which is always experienced by large-pore zeolites due to their more opened structures and low metastability (Step 4) [37,38]. Thus, a successive crystal phase transformation from SAPO- 5 to SAPO-41 with less opened structure occurs.

The induction, nucleation, crystal growth, and Ostwald ripening are also affected by other synthesis parameters. In particular, heating temperature has the most profound effect on those stages because increasing the reaction temperature will supply more energy to the 
system to ease breaking and new formation of $\mathrm{P}-\mathrm{O}-\mathrm{T}$ bonds $(\mathrm{T}=\mathrm{Al}, \mathrm{P}, \mathrm{Si})$, and directly increase the crystallization rate [24]. Furthermore, SAPO-5 may undergo different kinds of structural change via reconstructive phase transformation to a more metastable phase at high temperature. This is achieved by unit cell volume contraction through the removal of the water and/or [bzmIm $]^{+}$cations from the pores [22,39]. Furthermore, the addition of $\mathrm{SiO}_{2}$ as one of the primary building units also affects the entire crystallization process of SAPO-5. During hydrothermal treatment, the silicates compete with aluminates and phosphates in the construction of AFI framework where the former species affects the crystal growth orientation, forming SAPO-5 crystals with different shapes and sizes [40].

Furthermore, the $\mathrm{pH}$ of precursor hydrogel has been suggested to control the nucleation rate of SAPO-5, affecting the crystal size and purity. Large and intergrown SAPO-5 crystals with co-crystallized dense phase are obtained when the crystallization occurs under acidic environments (high $\mathrm{P}_{2} \mathrm{O}_{5} / \mathrm{Al}_{2} \mathrm{O}_{3}$ ratio or high $\mathrm{H}_{2} \mathrm{O}$ content) because of rapid hydrolysis and polycondensation reactions at low $\mathrm{pH}$ [41]. In contrast, when the crystallization takes place at nearly neutral environment $(\sim 6.0)$ in the excessive amount of [bzmIm] $^{+}$template, a supersaturation condition is formed. It thus facilitates rapid and homogeneous nucleation rather than crystal growth, forming SAPO-5 crystals with uniform and smaller sizes [42].

\section{Summary}

SAPO-5 microporous solids with defined morphologies and sizes were successfully synthesized using a new imidazolium template, [bzmIm] $\mathrm{OH}$. The effects of the synthesis parameters were systematically investigated. It was found that SAPO-5 undergoes four evolutionary processes, namely, induction, nucleation/propagation, crystal growth, and Ostwald ripening. Small SAPO-5 particles can be prepared with gel composition of $1 \mathrm{Al}_{2} \mathrm{O}_{3}: 2.5 \mathrm{P}_{2} \mathrm{O}_{5}: 2.5[\mathrm{bzmIm}]_{2} \mathrm{O}: 180 \mathrm{H}_{2} \mathrm{O}: 0.47 \mathrm{SiO}_{2}$ at $150{ }^{\circ} \mathrm{C}$ for $10 \mathrm{~h}$. These relatively low temperature, low water content, and concentrated template conditions favor nucleation over crystal growth. In contrast, the high molar ratio of $\mathrm{P}_{2} \mathrm{O}_{5} / \mathrm{Al}_{2} \mathrm{O}_{3}$ (low pH), high $\mathrm{SiO}_{2}$ content, long crystallization time, and high heating temperature favor the formation of big SAPO- 5 crystals and in most cases, tridymite and cristobalite dense phases are also formed. Similar to aliphatic amine templates, the SAPO-5 solids crystallized using [bzmIm] OH also exhibit hexagonal prism morphology. Hence, they are suitably used as advanced material in catalysis, membrane separation, sensor, heat pump, drug carrier and adsorption technologies. Comprehensive work on studying SAPO-5 in those aspects is in progress.

Author Contributions: I.A.A.: Performed most of the experiments, wrote the manuscript. F.K., T.C.L., K.-L.W. and E.-P.N.: Wrote and proofread the manuscript, supervised I.A.A., formed idea for the entire project, applied research funding. F.D. and S.M.: Ran XRD analysis, proofread the manuscript. All authors have read and agreed to the published version of the manuscript.

Funding: This research was funded by Universiti Sains Malaysia, grant number 1001/PKIMIA/8011128.

Institutional Review Board Statement: Not applicable.

Informed Consent Statement: Not applicable.

Data Availability Statement: The funders had no role in the design of the study; in the collection, analyses, or interpretation of data; in the writing of the manuscript, or in the decision to publish the results.

Acknowledgments: The financial support from RUI (1001/PKIMIA/8011128) grant is gratefully acknowledged. I.A.A. would also like to thank TETFund for the scholarship provided.

Conflicts of Interest: The authors declare no conflict of interest. 


\section{References}

1. Tosheva, L.; Ng, E.-P.; Mintova, S.; Hölzl, M.; Metzger, T.H.; Doyle, A.M. AlPO4-18 seed layers and films by secondary growth. Chem. Mater. 2008, 20, 5721-5726. [CrossRef]

2. Ng, E.-P.; Awala, H.; Komaty, S.; Mintova, S. Microwave-green synthesis of AlPO-n and SAPO-n ( $\mathrm{n}=5$ and 18$)$ nanosized crystals and their assembly in layers. Microporous Mesoporous Mater. 2019, 280, 256-263. [CrossRef]

3. IZA-SC Database of Zeolite Structures. Available online: http:/ /www.iza-structure.org/databases / (accessed on 26 January 2021).

4. Li, M.; Zeng, C.; Zhang, L. Hydrothermal synthesis of SAPO-5 with novel morphologies from hydrogels containing acetic acid and high concentration of triethylamine under neutral or alkaline conditions. CrystEngComm 2012, 14, 3787-3792. [CrossRef]

5. Gómez-Hortigüela, L.; Pérez-Pariente, J.; Corà, F.; Catlow, C.R.A.; Blasco, T. Structure-directing role of molecules containing benzyl rings in the synthesis of a large-pore aluminophosphate molecular sieve: An experimental and computational study. J. Phys. Chem. B 2005, 109, 21539-21548. [CrossRef]

6. Jiang, F.; Tang, Z.; Zhai, J.; Ye, J.; Han, J. Synthesis of AlPO4-5 crystals using TBAOH as template. Microporous Mesoporous Mater. 2006, 92, 129-133. [CrossRef]

7. Ng, E.-P.; Delmotte, L.; Mintova, S. Environmentally benign synthesis of nanosized aluminophosphate enhanced by microwave heating. Green Chem. 2008, 10, 1043-1048. [CrossRef]

8. Roldán, R.; Sánchez-Sánchez, M.; Sankar, G.; Romero-Salguero, F.J.; Jiménez-Sanchidrián, C. Influence of pH and Si content on Si incorporation in SAPO-5 and their catalytic activity for isomerisation of n-heptane over Pt loaded catalysts. Microporous Mesoporous Mater. 2007, 99, 288-298. [CrossRef]

9. Geng, L.; Dong, H.; Liu, X.; Zhang, B. Efficient manipulation of continuous AFI-type aluminophosphate membranes with distinctive microstructures on macroporous $\alpha-\mathrm{Al}_{2} \mathrm{O}_{3}$ substrates. Molecules 2018, 23, 1127. [CrossRef] [PubMed]

10. Auwal, I.A.; Mintova, S.; Ling, T.C.; Khoerunnisa, F.; Wong, K.-L.; Ng, E.-P. Crystallization profile and morphological study of SAPO-5 templated by imidazolium cations of different functional groups. Microporous Mesoporous Mater. 2020, 308, 110514. [CrossRef]

11. Khoo, D.Y.; Kok, W.-M.; Mukti, R.R.; Mintova, S.; Ng, E.-P. Ionothermal approach for synthesizing AlPO-5 with hexagonal thin-plate morphology influenced by various parameters at ambient pressure. Solid State Sci. 2013, 25, 63-69. [CrossRef]

12. Ng, E.-P.; Sekhon, S.S.; Mintova, S. Discrete MnAlPO-5 nanocrystals synthesized by an ionothermal approach. Chem. Commun 2009, 13, 1661-1663. [CrossRef] [PubMed]

13. Ng, E.P.; Itani, L.; Sekhon, S.S.; Mintova, S. Micro-to Macroscopic Observations of MnAlPO-5 Nanocrystal Growth in Ionic-Liquid Media. Chem. Eur. J. 2010, 16, 12890-12897. [CrossRef] [PubMed]

14. Ng, E.-P.; Wong, K.-L.; Ng, D.T.-L.; Awala, H.; Mukti, R.R.; Adam, F.; Mintova, S. AlPO-5 nanocrystals templated by 1-ethyl-2, 3-dimethylimidazolium hydroxide and their textural and water sorption properties. Mater. Chem. Phys. 2017, 188, 49-57. [CrossRef]

15. Khoo, D.Y.; Awala, H.; Mintova, S.; Ng, E.-P. Synthesis of AlPO-5 with diol-substituted imidazolium-based organic template. Microporous Mesoporous Mater. 2014, 194, 200-207. [CrossRef]

16. Ghrear, T.M.A.; Rigolet, S.; Daou, T.J.; Mintova, S.; Ling, T.C.; Tan, S.H.; Ng, E.-P. Synthesis of Cs-ABW nanozeolite in organotemplate-free system. Microporous Mesoporous Mater. 2019, 277, 78-83. [CrossRef]

17. Chen, Z.; Zhu, S.; Li, P.; Li, X.; Xu, Y.; Dong, Y.; Song, W.; Yi, X.; Fang, W. Fabricating self-assembled SAPO-5 with tailored mesoporosity and acidity using a single template. CrystEngComm 2017, 19, 5275-5284. [CrossRef]

18. Auwal, I.A.; Wong, K.-L.; Ling, T.C.; Ooi, B.S.; Ng, E.-P. Metal Chlorides Grafted on SAPO-5 (MClx/SAPO-5) as Reusable and Superior Catalysts for Acylation of 2-Methylfuran Under Non-Microwave Instant Heating Condition. Processes $2020,8,603$. [CrossRef]

19. Agliullin, M.; Kutepov, B. Selective Crystallization of AlPO 4-41 Molecular Sieve in the Presence of Diethylamine. Petrol. Chem. 2020, 60, 890-894. [CrossRef]

20. Ng, E.-P.; Awala, H.; Ghoy, J.-P.; Vicente, A.; Ling, T.C.; Ng, Y.H.; Mintova, S.; Adam, F. Effects of ultrasonic irradiation on crystallization and structural properties of EMT-type zeolite nanocrystals. Mater. Chem. Phys. 2015, 159, 38-45. [CrossRef]

21. Wragg, D.S.; Slawin, A.M.; Morris, R.E. The role of added water in the ionothermal synthesis of microporous aluminium phosphates. Solid State Sci. 2009, 11, 411-416. [CrossRef]

22. Hu, Y.; Liu, C.; Zhang, Y.; Ren, N.; Tang, Y. Microwave-assisted hydrothermal synthesis of nanozeolites with controllable size. Microporous Mesoporous Mater. 2009, 119, 306-314. [CrossRef]

23. Wong, S.-F.; Deekomwong, K.; Wittayakun, J.; Ling, T.C.; Muraza, O.; Adam, F.; Ng, E.-P. Crystal growth study of KF nanozeolite and its catalytic behavior in Aldol condensation of benzaldehyde and heptanal enhanced by microwave heating. Mater. Chem. Phys. 2017, 196, 295-301. [CrossRef]

24. Askari, S.; Siahmard, A.B.; Halladj, R.; Alipour, S.M. Different techniques and their effective parameters in nano SAPO-34 synthesis: A review. Powder Technol. 2016, 301, 268-287. [CrossRef]

25. Chen, J.; Wright, P.; Natarajan, S.; Thomas, J. Understanding the Brønsted acidity of SAPO-5, SAPO-17, SAPO-18 and SAPO-34 and their catalytic performance for methanol conversion to hydrocarbons. Stud. Surf. Sci. Catal. 1994, 84, 1731-1738.

26. Persson, A.; Schoeman, B.; Sterte, J.; Otterstedt, J.-E. The synthesis of discrete colloidal particles of TPA-silicalite-1. Zeolites 1994, 14, 557-567. [CrossRef] 
27. Brar, T.; France, P.; Smirniotis, P.G. Control of crystal size and distribution of zeolite A. Ind. Eng. Chem. Res. 2001, 4, 1133-1139. [CrossRef]

28. An, T.; An, J.; Yang, H.; Li, G.; Feng, H.; Nie, X. Photocatalytic degradation kinetics and mechanism of antivirus drug-lamivudine in $\mathrm{TiO}_{2}$ dispersion. J. Hazard. Mater. 2011, 197, 229-236. [CrossRef]

29. Garofalini, S.H.; Miller, A. Kinetics of tridymite formation. J. Cryst. Growth 1986, 78, 85-96. [CrossRef]

30. Wang, R.; Lin, C.; Ho, Y.; Leu, L.; Chao, K. Silicon species in a SAPO-5 molecular sieve. Appl. Catal. 1991, 72, 39-49. [CrossRef]

31. Erichsen, M.W.; Svelle, S.; Olsbye, U. H-SAPO-5 as methanol-to-olefins (MTO) model catalyst: Towards elucidating the effects of acid strength. Catalysis 2013, 298, 94-101. [CrossRef]

32. Xu, R.; Pang, W.; Yu, J.; Huo, Q.; Chen, J. Chemistry of Zeolites and Related Porous Materials: Synthesis and Structure; John Wiley \& Sons: Hoboken, NJ, USA, 2009.

33. Briend, M.; Peltre, M.; Massiani, P.; Man, P.; Vomscheid, R.; Derewinski, M.; Barthomeuf, D. Modifications of structure and Si environment upon heating of SAPO-5, SAPO-34 and SAPO-37. Stud. Surf. Sci. Catal. 1994, 98, 613-620.

34. Grand, J.; Awala, H.; Mintova, S. Mechanism of zeolites crystal growth: New findings and open questions. CrystEngComm 2016, 18, 650-664. [CrossRef]

35. Cundy, C.S.; Cox, P.A. The hydrothermal synthesis of zeolites: History and development from the earliest days to the present time. Chem. Rev. 2003, 103, 663-702. [CrossRef]

36. Wong, S.-F.; Awala, H.; Vincente, A.; Retoux, R.; Ling, T.C.; Mintova, S.; Mukti, R.R.; Ng, E.-P. KF zeolite nanocrystals synthesized from organic-template-free precursor mixture. Microporous Mesoporous Mater. 2017, 249, 105-110. [CrossRef]

37. Jorge, M.; Auerbach, S.M.; Monson, P.A. Modeling spontaneous formation of precursor nanoparticles in clear-solution zeolite synthesis. J. Am. Chem. Soc. 2005, 127, 14388-14400. [CrossRef]

38. Auerbach, S.M.; Ford, M.H.; Monson, P. New insights into zeolite formation from molecular modeling. Curr. Opin. Colloid Interface Sci. 2005, 10, 220-225. [CrossRef]

39. Kumar, A.; Molinero, V. Two-step to one-step nucleation of a zeolite through a metastable gyroid mesophase. J. Phys. Chem. Lett. 2018, 9, 5692-5697. [CrossRef] [PubMed]

40. Jhung, S.H.; Chang, J.-S.; Kim, D.S.; Park, S.-E. Effects of silica on the synthesis of AFI molecular sieve in acid and base conditions under microwave irradiation. Microporous Mesoporous Mater. 2004, 71, 135-142. [CrossRef]

41. Chen, C.-M.; Jehng, J.-M. Effect of synthesis $\mathrm{pH}$ and $\mathrm{H} 2 \mathrm{O}$ molar ratio on the structure and morphology of aluminum phosphate (AlPO-5) molecular sieves. Catal. Lett. 2003, 85, 73-80. [CrossRef]

42. Ng, E.-P.; Mohammad, S.A.G.; Rigolet, S.; Daou, T.J.; Mintova, S.; Ling, T.C. Micro-and macroscopic observations of the nucleation process and crystal growth of nanosized Cs-pollucite in an organotemplate-free hydrosol. New J. Chem. 2019, 43, 17433-17440. [CrossRef] 